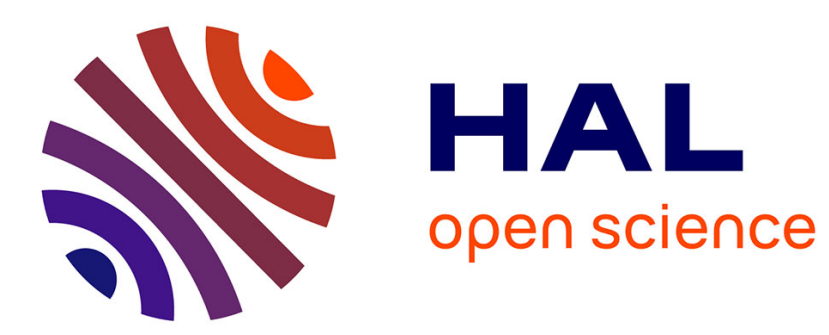

\title{
Continuous Mobility Surveys: The State of Practice
}

Juan de Dios Ortuzar, Jimmy Armoogum, Jean-Loup Madre, Françoise Potier

\section{To cite this version:}

Juan de Dios Ortuzar, Jimmy Armoogum, Jean-Loup Madre, Françoise Potier. Continuous Mobility Surveys: The State of Practice. Transport Reviews, 2010, first published nov 2010, 30p. 10.1080/01441647.2010.510224 . hal-00559503

\section{HAL Id: hal-00559503 https://hal.science/hal-00559503}

Submitted on 27 Jan 2011

HAL is a multi-disciplinary open access archive for the deposit and dissemination of scientific research documents, whether they are published or not. The documents may come from teaching and research institutions in France or abroad, or from public or private research centers.
L'archive ouverte pluridisciplinaire HAL, est destinée au dépôt et à la diffusion de documents scientifiques de niveau recherche, publiés ou non, émanant des établissements d'enseignement et de recherche français ou étrangers, des laboratoires publics ou privés. 


\title{
Continuous Mobility Surveys: The State of Practice
}

\author{
Juan de Dios Ortúzar \\ Department of Transport Engineering and Logistics, \\ Pontificia Universidad Católica de Chile, \\ Casilla 306, Código 105, Santiago 22, Chile
}

Jimmy Armoogum, Jean-Loup Madre and Françoise Potier

Department of Transport Economics and Sociology (DEST), French National Institute for Transport and Safety Research (INRETS), 94114 Arcueil Cedex, France

\begin{abstract}
In this paper we challenge the prevailing practice of conducting one-off cross-sectional mobility surveys, making a case for change on the basis of usefulness and cost-effectiveness. We believe that urban areas over say, one million inhabitants, should collect mobility data on a continuous basis as part of their efforts to guarantee sustainable development. This would allow them to gain a proper understanding of the pressing environmental and transport-related issues of today's world, as well as of the effects of economic growth and price (especially for fuel) volatility. In our scope we include panel data (i.e. information from a smaller sample of respondents who are interviewed at different points in time, hopefully during several years), as this type of information is unique in its ability to help understanding behavioural changes and the impact of time-related effects, such as habit and inertia. We revise the state of affairs in different parts of the world, not limiting ourselves to urban data.
\end{abstract}

\section{Keywords}

Continuous surveys, on-going surveys, panel surveys. 


\section{Introduction}

Changes in behaviour are necessary to reverse the worrying long-term trends of growing mobility, with increasing oil consumption and global greenhouse gas (GHG) emissions. In most countries, including some of the most wealthy and advanced, conventional crosssectional travel surveys are conducted roughly once a decade (i.e. they are "one-off" exercises) and only one weekday is surveyed for each respondent in "representative" periods when traffic flows are maximal. This is not enough to gain a proper description of the above long-term trends, as well as of changes in behaviour. Neither it is possible to properly analyse these types of issues with such limited data. Furthermore, mobility surveys need to use evolving methodologies to keep up with good practice standards (Stopher et al., 2006); this hinders the comparison between subsequent surveys for the assessment of trends (e.g. the American Nationwide Personal Travel Survey - NPTS - shifted from a trip-based to an activity-based approach). One-off surveys are also subject to unpredictable events (e.g. strikes or extreme weather conditions) and do not allow a clear distinction between long-term trends and short-term events (economic boom or recession). For instance, several National Travel Surveys have been conducted during the 2008-2009 recession: are their results comparable to those collected a decade before?

Good quality travel data are needed both to portray existing situations and to help identifying problems related to the operation of today's increasingly complex transport systems; they are also important to estimate the models that are quintessential for urban and regional planning, especially to give them a real dynamic dimension. In fact, the most typical (and difficult) need has always been for data to calibrate the large strategic transport-models used in long-term project evaluation and environmental assessment.

Based on reasons of usefulness and cost-effectiveness, we wish to challenge the practice of using one-off cross sectional surveys and make a strong case for change. We believe that all urban areas over a certain limit (say one million inhabitants) should be involved in collecting mobility data on a continuous basis as part of their efforts to guarantee sustainable development. We argue that continuous travel surveys, where mobility is described along a relatively long period of time, are indispensable to gain a proper understanding of the complex issues faced by contemporary planners (see also, Zumkeller and Ottmann, 2009).

Ampt and colleagues (Ampt and Ortúzar, 2004; Ampt et al., 2009) have discussed the stateof-practice of a new breed of large-scale urban surveys that go a long way towards addressing 
some of the abovementioned deficiencies: the on-going mobility survey. In this case, data for each respondent are sought for the 24 hours of the day in the seven days of the week and in all seasons of the year; further, the effort should be kept going for several years. Ampt and colleagues concentrated on two main areas: methodology: data collection issues (including types of surveys, e.g. self-completion vs. personal interviews, sample selection), questionnaire design and survey content; and challenges of current practice: decreasing response rates, respondent burden, weighting and expansion methods and uses of the data.

Apart from doing a survey of applications of continuous surveys throughout the world (looking at issues that were not considered by Ampt and colleagues) in this paper we include data panels under the general label of "continuous" survey. Panels offer another possibility to understand behavioural changes (and the impact of time-related effects such as habit and inertia in transport); by panel data we mean information from a generally smaller sample of respondents who are interviewed several times at different points in time, hopefully over several years (Tourangeau et al., 1997; Stopher et al., 2009; Zumkeller and Ottman, 2009). We consider also examples (albeit there are few) of regional and national surveys in the two classes above.

In the next sections we will consider why conducting a travel survey on a continuous basis is worthwhile (section 2). However, although there are many advantages associated with collecting mobility data on a continuous basis, managing to do it in practice is not that easy. In section 3 we review the state-of-practice in continuous travel and panel surveys at the urban, regional and national levels. Researchers from different countries, where continuous surveys and panels are on-going/starting/abandoned shared with us their experience; this effort was prompted by a seminar organized at INRETS by the COST Action 355, was updated through an e-mail survey to all parties known to be engaged in such efforts, including Africa, Latin America, the Far East, India and South East Asia, and was completed during another seminar organised in Paris for the COST TU0804 SHANTI (Survey Harmonisation with New Technologies Improvement) project in September 2009.

Section 4 analyses some methodological advantages and drawbacks of continuous survey approaches in terms of sampling issues (i.e. subsequent cross-sections vs. panel surveys, sample size, etc.). Section 5 considers issues related with survey administration (i.e. how to deal with training and fatigue of interviewers and what to do with declining response rates). Finally, in section 6 we present our main conclusions, trying to address some of the key issues for reflection posed by Ampt et al. (2009). 


\section{Why a Continuous Data Collection Effort?}

Batellino and Peachman (2003) have put this case succinctly:

"A continuous survey provides data on trends in travel patterns and behaviour which reflect changing social and economic conditions ... point data reflect only those conditions at that point in time and provide no information about the intervening trends between points. This is a particular problem if those points are far apart ... and of even more concern if they happen to coincide with markedly different phases of the economic cycle”.

This was precisely what had happened in Sydney before their continuous survey started in 1997, as unemployment was much higher in 1991 than in 1981 (date of the two previous conventional surveys), with different impacts on male and female behaviour. In France, on the other hand, the National Travel Survey 1973-74 started one month before the war which caused the first oil crisis and the 1993-94 survey was conducted during the recession and a major disturbance of the railway ticketing system. Since 2006 with high fuel prices, mobility has been lower than before in large French conurbations, but walking and cycling have received a larger modal share (Hubert, 2009).

In a continuous survey the specificity due to unpredictable events can be checked by comparing with other periods in the year. Surveying over the entire year allows controlling for seasonal effects (e.g. long distance trips for holidays, bicycle use, walking, etc.). Moreover, subsequent years can be aggregated for the analysis of sub-groups (e.g. regions), and a flexible design allows considering additional questions for specific studies, over just a short period.

Another deficiency of one-off surveys is the unavoidable loss of staff and knowledge in the inter-survey period, which has to be re-established for the next survey. Large scale household travel surveys are expensive projects to mount and resource intensive to manage. They require a considerable amount of in-house expertise in the design and management of the survey and the processing and analysing of the data. Setting up a team requires substantial investment in recruitment, training and development of staff. Much greater value can be derived if that team is employed on an ongoing basis rather than for the one-off large scale survey. This applies to both project management staff in the government (or research) organization conducting the survey and staff in the market research organization, or research institution, collecting the data on site. British experience reveals that it is more important that the team remains the same at 
the sponsor level, even if the field organization changes after a new tender.

Apart from the potentially large cost-inefficiency of knowledge loss, the differences in organizations/staffing between surveys increase the difficulty of having accurate measurement of changes in travel behaviour. Indeed, there is less turn-over in research institutes than in administrations or marketing research firms; thus, researchers have often the best information on past surveys. So, are changes recorded in time series partly reflecting differences in the quality of survey processing rather than real changes? Measuring the general extent of this effect is difficult, and quantifying it accurately is impossible. However, its extent is undoubtedly minimized by maintaining relative continuity of staff and procedures.

Finally, budgetary implications are also an important consideration in deciding to move to a continuous survey. It is easier to obtain funds when up and running (each year almost the same budget), than for one "big bang" survey. With surveys taken every so many years, there are uneven requirements for funds, so large amounts have to be arranged for at the time of the survey. If the political climate is not conducive to providing this funding, the survey could be delayed or not undertaken at all. On the other hand, a withdrawal of funding may occur at any time during a continuous survey; however, if it is progressing successfully and producing relevant results, its prospects of continued financing are enhanced as shown in practice, in particular in Australia, Germany (MOP panel survey), The Netherlands and UK. One particularly appropriate avenue to secure continuing funding is to expand the number of users of the data collected by the commissioning organization, such that they can contribute to the costs of acquiring information in subsequent years (Ampt et al., 2009). Finally, we also expect significant economies of scale from undertaking the survey on a continuous basis.

\section{Continuous Surveys Around the World}

At the national level, continuous data collection efforts have been conducted for many years in Germany, The Netherlands and UK, and more recently in New Zealand, Italy and the USA (although the American Community Survey asks for much more than a typical travel survey). However, some countries have also stopped conducting continuous surveys at the national level, i.e. Denmark, but just started again; Sweden, which is planning a new venture for 2010; and The Netherlands which stopped the well-known Dutch Mobility Panel (LVO) after 10 waves, but still conducts the National Travel Survey on large samples.

Notwithstanding, several urban areas in Europe (Austria, Belgium and Germany) have started new continuous surveys since the mid-90s and some others are planning new ventures as well 
(Madre, 2005). As shown in Table 1, outside Europe only Australia, Canada and Chile have joined this group.

\section{Table 1 approximately here}

So, it is probably fair to say that the idea of continuous data collection is progressing as witnessed by the American Community Survey that started in 1996 with a sample of counties and now covers the whole USA (www.census.gov/acs/www/), the French rolling census (www.insee.fr/fr/methodes/default.asp?page=definitions/enquete-de-recensement.htm) which started in 2004, and the European Community Household Panels conducted by EUROSTAT (1994-2001, followed by the SILC (Statistics on Income and Living Conditions) panel survey which started in 2004 (http://epp.eurostat.ec.europa.eu/portal/page/portal/microdata/eu_silc); all these are good examples of this trend.

\subsection{Nationwide on-going mobility surveys}

Starting in 1978, the National Mobility Survey in The Netherlands is probably the longest standing continuous survey; however, it was re-designed in 1985, 1998 and 2004 (Van Heukelingen, 2005), and again in 2009, because of an increasing unwillingness to participate, declining telephone accessibility (more unlisted numbers), and requests for continuity and comparability (i.e. a more flexible design).

During nearly 10,600 days up to 2008, more than 800,000 households (i.e. about 1.8 million people) described almost 6 million trips made during one designated day by all household members. In 1995, the sample size was expanded six-fold to accommodate regional estimates, and between 2004 and 2008 nearly 129,500 households (i.e. 296,500 individuals) were interviewed (Table 2). The survey excludes mobility during holidays and abroad.

\section{Table 2 approximately here}

The National Travel Survey (NTS) in England, Scotland and Wales has been conducted continuously since July 1988, after five one-off surveys between the 60s and mid-80s, and was extended to Northern Ireland in 1999. It is a 7-day self-completion travel diary for all household members, with an additional interview in the case of long distance trips for a longer period. The sample size was increased from 5,040 households/year in 1998 to 15,000 in 2002 and onwards, and the overall response rate in 2007 was $61 \%$, but higher in the rest of the country (63\%) than in inner (47\%) or outer (55\%) London (Anderson et al., 2008). 
The Danish National Travel Survey has been conducted by Statistics Denmark since 1992 with 14-16,000 computer-assisted telephone interviews done annually. The sample is randomly selected from the central person register. In 1998 an unexpected drop in $\mathrm{km}$ travelled and number of trips/person was observed; this trend, diverging from traffic counts, persisted in the following years. The main cause was a large rise in the number of people who declared staying at home all day. A smaller part was due to a decrease in trip rates for people actually making trips (Christensen, 2004).

Thus, it is important to keep a close check on the quality and results of the interviews. The percentage of zero trips, the trip rates and $\mathrm{km} /$ trip has to be controlled carefully both with respect to general trends and in relation to interviewer performance. This is a particularly serious problem in the case of continuous surveys that are vulnerable to breaks in trends due to changes in procedures or performance. After correcting these problems, Denmark started a new continuous survey in 2006, but moving from activity-based to trip-based, not involving their National Statistic Bureau, and with objectives more focussed on environment and modelling than on long term trends. The sample scheme is more strictly stratified for a more accurate estimation of annual changes.

The New Zealand Travel Survey (www.transport.govt.nz/research/TravelSurvey/) began in mid 2002 and is supposed to last indefinitely. Household residents have to record their travel for a pre-specified 2-day period. The sample size was 2,200 households/year between 2002 and 2007, and was increased in 2008 to 4,600 households/year. In addition, the main cities of the country contribute to having an expanded sample contacted in their areas since 2008. Response rates have been lower than in previous one-off surveys, but are still quite high: 66\% for complete households and around $70 \%$ if data are not obtained for all household members.

In Italy, the Istituto Superiore di Formazione e Ricerca er i Trasporti (ISFORT) conducts the Audimob (Italians' Mobility Behaviour Observatory) national survey since 2001. Approximately 15,000 telephone interviews are conducted each year randomly sampling every three months. The survey combines quantitative aspects (how, where and why do Italians travel) with qualitative and behavioural profiles about their mode choice, their perceived satisfaction and evaluation of critical factors affecting travel (http://www.isfort.it/).

In other countries continuous surveys are not currently conducted nationwide, but mostly at a regional level, on wide enough areas to allow considering urban sprawl, which is a major determinant of travel behaviour changes. 


\subsection{A growing effort at regional/metropolitan level}

The Victorian Activities \& Travel Survey (VATS) in Melbourne was the first on-going metropolitan mobility survey, and inspired all the rest. It began in 1993 with an initial five year horizon but lasted officially until 2002 (Richardson et al., 1995; Richardson and Ampt, 1993). In 2007 a new initiative, the Victorian Integrated Survey of Travel \& Activity (VISTA) was launched, with about 15,000 households in Melbourne and several regional areas of Victoria being interviewed during the whole year; this was followed up by a new 12 month survey in 2009 (www.transport.vic.gov.au/vista). So, while not fully continuous, it is getting close with 12 months on and 12 months off. Further, given the level of transport investment in Victoria, it appears that VISTA will become a permanent feature of the transport planning landscape, much like VATS in the $90 \mathrm{~s}^{1}$.

The second Australian experience was the Sydney Household Travel Survey (HTS), a continuous effort started in 1997 which is still going strong. Battellino and Peachman (2003) provide an excellent description of its genesis plus incisive comments about the advantages and practical problems faced when developing such a large-scale on-going survey. The aim of HTS is to interview 5,000 households/year but usually slightly less (i.e. 4,800 to 4,900) are reached because of sample loss (vacant dwellings, dwellings under construction); this means that approximately 13 households/day are surveyed. Response rate has been declining and in recent years it is only 56\% for complete households and 64\% if partial response is considered.

Following completion of the South-East Queensland Travel Surveys in 2003-04 for Brisbane, the Gold Coast and the Sunshine Coast, the regional government decided to adopt a semicontinuous survey format from 2006 onwards. The Urban Transport Institute (TUTI), in association with I-view Pty Ltd., designed and conducted the surveys from 2006 through 2008 and were commissioned to repeat them in 2009 (www.tuti.com.au/SEQTS09.html). These were conducted in April-June 2009 within the Brisbane Statistical Division (3,500 responding households), and in July-September 2009 both in the Gold Coast (3,000 responding households) and in the Sunshine Coast (3,000 households). Response rates have been in the range of 50 to $60 \%$ in these surveys.

The format of the 2009 surveys was very similar to that adopted for the 2003-04 and 2006-08 surveys (to enable ease of comparison and/or aggregation of the data), and was based on a self-completion activity/travel diary for one day, supported by personal delivery and pickup of the questionnaires.

\footnotetext{
${ }^{1}$ Tony Richardson (2009) Private communication.
} 
In Europe, six continuous all-year surveys have been conducted by Socialdata in Germany or Austria using the New Kontiv diary design (four are still on-going in Halle, Nuremberg, Vienna and Bungerland/Lower Austria). The starting premise of this design is that "the researchers must adjust to the respondents, not the respondents to the researchers”. The diary is designed to obtain all information concerning out-of-home activities performed on one (pre-specified) day. Since diaries are best filled out by the respondents themselves, the survey is self-administered and has to be mailed-back. The telephone is used more to motivate and check than to question. This combination ensures both high and constant response rates (about 70\%) over the years. Finally, in-depth individual interviews are also "attached" as separate studies to determine reasons for mobility behaviour, to assess potentials for change and to evaluate adequate measures in qualitative and quantitative ways.

In Montreal a continuous survey started in January 2009, just after the completion of a large traditional survey (66,000 households) held in the autumn of 2008. This survey will initially run for three years with an intended sample size of 15,000 households per year².

\subsection{Panel surveys}

Panel mobility surveys exist at a national level only in Germany (Zumkeller et al., 2006; Zumkeller, 2009). In between the large Mobility in Deutshland (MiD) cross-sectional mobility surveys (about 50,000 households in 2002 and 2008), the German Mobility Panel (MOP) has collected data through 7-day self-completion diaries. Each year about 350 - 400 "fresh" households are recruited to stay for a total of three years within the panel; so the approach constitutes a 3-year rotating panel. Within these cohorts, an attrition rate of about 25 - $30 \%$ has been found on average. With a cohort size of about 350 "fresh" households/year each transition from one year to the next comprises about 450 households, which are "repeaters", and a total sample size of about 750-800 households/year. During the set up phase (1994 1999), the survey was conducted only in former Federal Republic and then it was extended to the "new" states of the former GDR. This late extension was the result of lack of ITinfrastructure for surveying in the former East Germany (e.g. lack of private phones at the beginning).

The competing objectives of the MOP led to the following compromise: representativeness could be achieved by the panel rotation and the dropping out of some participants. An attempt to reduce burden was made by limiting the reporting of activities and trips (the survey use a

\footnotetext{
${ }^{2}$ Daniel Bergeron (2009) Private communication.
} 
one-week diary) such that only residence address was captured in enough detail to be geocoded. Plausibility checks of reported behaviour were performed at different stages of the survey and data processing, and the selection bias is analysed along the recruitment process.

In The Netherlands, although interrupted, the Dutch Mobility Panel (LVO) is important because its number of waves (10) and sample size (between 1,687 and 1,928 households/wave) characterize it as the largest transportation panel ever. It started in 1984 and ended in 1989 (BGC, 1991; Banders and Slootman, 1982), and was independent from the still on-going continuous cross-sectional survey described above. This survey was not driven by a specific purpose; it was used as a universal instrument for data supply and analysis, and designed as a multi-purpose panel, since it was both multi-period (participants reported every half year) and multi-day (one-week trip diary was filled). Besides the trip diary, with detailed reporting of origins and destinations, people answered many questions in a personal interview which included both retrospective questions and questions about long distance travel. However as a result of this, probably too high respondent burden, the willingness to participate was low and the willingness to report more than one wave showed attrition rates up to $47 \%$ between two waves. The sample frame did not represent the population but over sampled interesting household groups such as transit customers.

Thanks to its scientific potential the LVO has been well documented and the experience used subsequently for other panels such as the German Mobility Panel (Golob et al., 1997). Other panel surveys exist for long distance travel (INVERMO in Germany and SDT Follow-up of Demand for Tourism in France) and for gas consumption (i.e. the Parc-Auto and SECODIP panel surveys in France). More details can be found in Zumkeller et al. (2004).

In the USA the New York Metropolitan Transportation Council is considering a panel component in their forthcoming large cross-sectional household survey ${ }^{3}$.

Finally, an interesting panel data collection effort took place recently in Santiago, Chile, taking advantage of the impending implementation of Transantiago (Muñoz et al., 2009), a radically new public transport system for the city. As it turned out, the new system was badly implemented in February 2007 causing chaos (this is not an exaggerated statement) in the city during months; Transantiago is now reaching steady state conditions and all changes experienced since December 2006 (when the first wave of the Santiago Panel was taken) were "recorded" by the four waves of the panel (Yáñez et al., 2010b). This is the first travel

\footnotetext{
3 Johanna Zmud (2009) Private communication.
} 
panel constructed in Latin America and the first in the world specifically devoted to mode choice analysis with more than two waves. The data has served to analyse changes generated by this new policy in users' behaviour, and also to formulate and estimate advanced discrete choice models considering inertia and shock policy effects (Yáñez et al., 2009).

\subsection{Interrupted Mobility and Panel Surveys}

\subsubsection{Cross sectional surveys}

Cross-sectional surveys have stopped in Sweden, Leipzig and Wiesbaden, Perth and Santiago de Chile. In Sweden, after two one-year surveys (1978 and 1985), the Swedish Institute for Transport and Communications Analysis (SIKA) started a continuous National Travel Survey (NTS) in 1994, and kept going until 2001. Mobility data was collected on a pre-specified day and data on long distance travel ( $>100 \mathrm{~km}$ ) was collected for a longer recall period (1 month/2 months), as well as on tele-work and flexible working arrangements. SIKA made an evaluation of the survey performance finding four main areas of limitations in the use of a continuous NTS:

- despite a relatively large sample (8,000 individuals per year), only large changes could be detected on a yearly basis; indeed, the sample was not stratified (independent samples drawn quarterly as simple random sample);

- data quality declined because of competence loss in key positions and in interviewers' performance; the longer the survey period the bigger was the problem;

- considering changes in the questionnaire for the construction of the database and updating data on supply for modelling, was difficult and costly at a national scale;

- the use of tele and video-conference and access to intelligent communication tools (ICT) grew rapidly in a few years and the need to analyze how this affected the organization of work and leisure, the demand for travel and travel patterns, became necessary; this topic was also introduced in the Puget Sound Transportation Panel in 1997.

The survey ended in 2001 and SIKA launched a new data collection system in 2003, covering both travel and ICT. This consisted of two full year surveys conducted alternating every second year:

- the National Communications Survey (2003, 2007), NCS, covered travel and other communications with a sample of about the same size as the former continuous survey;

- the National Travel Survey (2005), NTS, covered only travel behaviour but used a much larger sample, 41,225 individuals. 
SIKA is not planning to conduct further NCS in the future, as results could not be used as planned. However, through the NCS they became aware of how sensitive the data was to bias by differences in methods. This is one reason why they decided to conduct the next NTS continuously again. They hope to achieve greater stability in their methods, because the organisation conducting the survey will get better routines and if there are changes in methodology (i.e. because technology allows it), it will be easier to figure out its impact if the survey is continuous rather than if there is a gap of several years in between ${ }^{4}$.

Among the six urban mobility surveys conducted by Socialdata, two have been interrupted: Wiesbaden in 2003 and Leipzig in 2001 (these were only planned for three years). In that period there were changes at the client (new staff), and the new managers were not interested in continuous surveys. This confirms the importance of a motivated staff, which has also been mentioned in the case of Sweden.

The on-going Santiago Mobility Survey in Chile started in 2001, operated for a year, stopped (mainly for political reasons) for one and a half years, and came back to course in 2004 for another three years. During the first wave (2001-2002) some 15,000 households were interviewed; origin-destination data were also gathered at 150 intercept points for travellers by all modes (including walking and cycling) as well as all-day traffic counts (peak and offpeak classification and occupancy factors) at external and internal cordons. Response rates were very high (70\%) thanks to careful adherence to survey design specifications (Ampt and Ortúzar, 2004).

From April 2004 until its end in mid 2007, a sample of 5,000 households was interviewed (www.sectra.cl/contenido/bases_datos_sig/encuestas_movilidad/encuestas_grastgo.htm) every 12 months as planned; intercept surveys (which had proved very costly in the 2001 survey) were only taken in 2006 However, due to ill-thought cost-saving reasons the strict, almost online, procedures for data entry and checking were relaxed and performed not every day or week, but every month and later every several months. This meant that finding out an interviewer performing incorrectly (for example, much lower trip rates), took 3-4 months to detect. This led to severe data loss, replacement of personnel, re-training of interviewers, higher costs and the need to apply non-trivial correction factors to non compulsory trips. Also, a substantial amount of data - pertaining to 2006, the all-important year before Transantiago was implemented - had to be deleted and eventually replaced with newly collected data for 2007. Response rates fell dramatically to some $45 \%$ (see the in-depth discussion in Ampt et

\footnotetext{
${ }^{4}$ Linnea Abramowski (2009) Private communication.
} 
al., 2009). Chilean government officials were studying whether to continue the survey, but since a new government was appointed in March 2010 the decision was delayed.

The Perth and Regions Travel Survey (PARTS) ran for four years, as planned, after starting in October 2002. Hill et al. (2004) provide a good summary of the survey characteristics. A special feature was that the study area is a region much larger than the metropolitan area, a requirement for analysing urban sprawl. The sample size was 2,350 responding households/year and the survey used a self-completion form delivered personally to the household. Like in Sydney, a cluster sampling system aimed at being geographically and chronologically balanced was used but the structure of the survey and data collection methods were standard.

\subsubsection{Longitudinal surveys}

The Puget Sound Transportation Panel (PSTP) in Seattle ran 10 waves between 1989 and 2002 (www.psrc.org/data/surveys/pstp-survey/). It was designed as a general purpose urban household panel mainly focused on transportation, but also served as a tracking device for the dynamics of employment, work, household composition, vehicle availability, travel behaviour, attitudes and values (Murakami and Watterson, 1989; Murakami and Ulberg, 1997; Kilgren, 1998). As it was not set up regularly (there were two year gaps between some waves and the survey season was not always the same), certain patterns and figures emerging from it are not strictly comparable. Nevertheless, it showed the feasibility of a panel over a time span of more than a decade with the same participants. The permanent refreshment kept the sample size at about 1,500 - 2,000 households/wave.

The data available for analysis purposes in the PSTP included household and individual information plus detailed records from a 2-day travel diary (to limit fatigue effects). This raised questions about the limited amount of variance covered on a day-to-day basis. In particular, it was questioned whether two days would be enough for an accurate measurement of travel behaviour changes between subsequent waves of the panel. Since 1997 the original objectives were enriched by the introduction of questions on traveller information system use, telecommunications and computer ownership and use. Furthermore, a shift from a trip based to an activity based approach was also introduced. These two enrichments clearly raised issues about comparability, but for a sample with known characteristics the addition of such questions made sense as much comparable information for other survey items was available. The survey was stopped because data were mainly used by academics and no real usage was being made by government or consultants; moreover, no extra measurements (i.e. level-ofservice) were taken for each wave, diminishing the potential use of the data in modelling and 
planning. The high cost associated with collecting data on transport supply has also been mentioned as a reason for interrupting continuous data collection in Sweden.

In the USA a panel survey was also conducted for at least two years (1998 and 2002) by the Metropolitan Washington Council of Governments, but it ceased eventually and there are no reports about it ${ }^{5}$. There are also examples of before and after surveys for pricing projects using a panel design; for example, the Puget Sound Traffic Choices Study observed the driving patterns of about 275 volunteer households before and after hypothetical tolls were charged for using all major freeways in Seattle (www.psrc.org/assets/37/summaryreport.pdf); the panels for the I-15 and SR-91 projects in Southern California (back in the mid 1990s) and a panel survey for the MnPASS HOT Lanes in Minneapolis, in this case, one before wave and two after waves (Bradley and Zmud, 2006).

In Canada two sophisticated panel surveys about daily activity behaviour were conducted this century. The first in Toronto had three waves each lasting 12 months, between 2001 and 2004 with an initial sample of some 300 respondents and relatively high attrition (partly explained by the survey complexity, see Lee-Gosselin, 2005). The second was conducted in Quebec city (Lee-Gosselin and Miranda-Moreno, 2009; Miranda-Moreno and Lee-Gosselin, 2008), also ran three waves, each lasting 12 months between 2002 and 2005; the first wave considered 250 households who were observed for seven days, asking about their daily activities with the aim of establishing spatial and temporal flexibility in activity patterns. These dropped to 200 in the second wave and to 171 in the third; so, there was $80 \%$ retention from wave 1 to wave 2 , and $86 \%$ retention from wave 2 to wave 3 (i.e. total attrition was $32 \%$ ). This was, again, judged acceptable given the enormous respondent burden in the first wave.

In Adelaide, Australia, approximately 1,000 households participated in a fairly revolutionary panel (using odometer data) from October 2004 to October 2007, with a total of nine waves (every four months); the study aim was to evaluate voluntarily users' travel behaviour change programmes (Stopher and Swann, 2008). Another 3-year GPS panel ran at the same time (Stopher et al., 2008a; Stopher, 2009; Stopher et al., 2009). Finally, there is an on-going 6wave GPS panel to determine the longer-term (5+ years) sustainability of travel behaviour changes from a variety of TravelSmart projects in six Australian states. It has about 130 households carrying GPS devices for all travel for 15 days once each year; everyone over the age of 14 is provided with a small portable logging GPS device ${ }^{6}$.

\footnotetext{
${ }^{5}$ Elaine Murakami (2009) Private communication.

${ }^{6}$ Peter Stopher (2010) Private communication.
} 
In Spain there is evidence of at least two panels. Between 2002 and 2003 the first had three waves and 143 respondents; it was designed to study season ticket use in the Valencia metropolitan area (Ruiz, 2004). The Madrid-Barcelona Corridor Panel (M-BCP), although interested in long distance travel and not daily mobility, was a multiday and multi-period biannual survey initiated in 2005 and finished in 2007 (Ruiz et al., 2008); it started with 3,480 panellists and ended with 1,986 (but only 1,338 remained during the four waves of the panel). Respondents were contacted by phone and interviewed using a specially designed CATI protocol. The main objective of this panel was to study changes in modal shares while highspeed rail services were being introduced in the corridor.

In Japan a series of seven panel surveys were taken between 1987 and 2005 seven waves (1987-1997) and was used to evaluate travel behaviour changes caused by an automated railway (AsTram) connecting a newly developed suburban area to the CBD in Hiroshima. The largest had nine waves (1989-1997) and was used to measure the effects on shopping behaviour caused by the opening of a new shopping complex in Kofu. The last one had only two waves (2003-2005) and was used to assess the behavioural changes of registrants of special transport services (i.e. aged or disabled people) in Okayama.

\section{Sampling Issues}

We have considered two main strategies for estimating trends:

- panel surveys, with a relatively small sample, where the same individuals are interviewed several times in different periods, and

- larger cross-sectional samples, drawn independently each year, and which can be spread all over the year.

The choice between these two approaches depends mainly on the correlation between subsequent occasions for the variable of interest and cannot be determined a priori. Surveys are typically taken because of an interest in the following issues: (i) getting a picture of individual mobility behaviour at a given moment in time; (ii) following up individual mobility behaviour for a long time; (iii) following up the global evolution of mobility behaviour.

The last is particularly important if the final aim of the study is the promotion of public transport for specific groups (e.g. young people, seniors, tourists, women with children), for

\footnotetext{
${ }^{7}$ Kuniaki Sasaki (2009) Private communication.
} 
specific trips (e.g. home-to-work, leisure) or for specific days (e.g. Mondays, Wednesdays, holiday periods). Now, following the global evolution of mobility behaviour is one of the main reasons for using permanent samples, as these may lead to improved estimation since they provide us with better measurements than successive independent samples.

For example, for a given household there would probably be negative correlation between buying a car one year and buying another in the next year. Thus, there is a conflict between the measurement of the parameter itself and the measurement of its evolution (Cochran, 1977). If correlation is positive and in both cases measurements are made with equal precision, detecting a significant evolution in parametric terms would be less costly with a permanent sample. But under the same conditions, the quality of the estimated parameter should be lower when using a permanent sample due its smaller size; therefore, improving estimation requires increasing sample size and, hence, the cost of the survey.

Note that the correlation coefficient depends on the time between two successive surveys. However, few studies seem to have detected this influence, so it is difficult to determine the length of the period between two series of surveys which will optimize the precision of the results.

\subsection{Panel surveys}

Long survey panels consist of repeating the same survey (i.e. same methodology and design) at "separate" times, for example once or twice a year for a number of years or before-andafter an important event. Short survey panels, are multi-day data where repeated measurements on the same sample of units are gathered over a "continuous" period of time (e.g. seven successive days), but the survey is not repeated in subsequent years (Axhausen et al., 2002; 2007); we do not consider these here.

Although the permanent sample gives an effective measurement of the evolution of some parameters, it presents some drawbacks, such as selection effects and the modification of the "long run” behaviour of permanent sample members. Moreover, long survey panels exclude new units (e.g. young households) and disappearing units (e.g. elderly passing away or moving to an institution). That is why rotating panels can be more representative of the population and less subject to attrition (i.e. loosing respondents) between successive panel waves. Treating panel attrition with a refreshment strategy is not the same as a panel rotation strategy: rotation allows the planned maintenance of the sample stratification in ways that are more desirable than refreshment strategies used when panel participation is open-ended. 
Rotation panels are also subject to attrition, but the self-selection that usually accompanies it is likely to be less of a problem.

The characteristics of both long and short survey panels can be combined, following respondent behaviour for several days each wave. Fatigue is a problem here as individuals get tired of keeping detailed records of their journeys after a few days. The Santiago Panel had precisely this characteristic, but concentrated only on work/study trips, asking questions about the potential influence of further activities on these trips at a second stage of the questionnaire. Furthermore, a recent study has shown that if the main interest of a panel was in modelling mode choice, the ideal length of the short survey component could be just one week, provided the sample is not too small (Cherchi et al., 2009; Yáñez et al., 2010a). Indeed, one week is an adequate time period for comparing successive waves of a long survey panel, as it offsets changes due to day to day variability (Zumkeller and Ottmann, 2009). Finally, GPS support reduces the respondent burden of multi-day panel surveys and increases the accuracy of measurement, especially for picking up short distance walk and cycle trips (Stopher et al., 2009).

\subsection{Continuous cross-sectional surveys}

In this case stratification is essential for a higher accuracy of estimates. For instance in Sydney, the sample is selected for three annual waves based on a stratified multistage cluster sampling method. Districts inside zones are selected using probabilities proportional to size and are divided into blocks of approximately 50 dwellings each; then one block is randomly selected and inside it seven dwellings are drawn; finally these dwellings are allocated to a different day of the week to ensure a balanced sample in time and space. In the Santiago Mobility Survey up to 2007, the randomness in time and space was achieved using twodimensional Sobol low-discrepancy sequences (see Ampt et al., 2009 for details) and the sample was also generated for three years (i.e. 15,000 addresses every three years).

Given the discussion above, the main issue appears to be the choice between a panel survey and successive cross-sections. Travel surveys, especially at a national level, are expensive to carry out so their sample sizes are usually limited. On the other hand, as most changes in travel behaviour are relatively small from year to year, only changes of greater amplitude can be detected at an aggregate level on a yearly basis. For example, even the large sample size in Sweden (8,000 individuals/year) did not allow meeting the survey objectives of using the data for detecting underlying trends in travel behaviour and to follow the overall travel developments over time. Also, although changes (in both directions) are larger at an 
individual level, they might only be detected through panel data.

The variability of travel over multiple days can be more easily identified with the help of new technologies. For example, Stopher et al. (2008a) administered panels using GPS devices and was able to examine the magnitude and significance of changes in travel behaviour detecting changes by mode of transport.

\section{Is it Possible to Avoid a Decline in Response Rates?}

Continuous surveys are more attractive to high quality marketing research companies, because of reduced learning curves for interviewers. In Great Britain, interviewers are briefed every year to refresh them, and some are rotated. In New Zealand, interviewers are refreshed in their training two days a year. In the first stage of the Santiago Mobility Survey, interviewers were trained during two weeks and rotated by sector (as high income zones with security agents controlling the access and low income zones with more criminality, were more difficult to work in). Moreover, interviewers may play a key role in obtaining full coverage of the population: for instance, they can help to fill in self-administered questionnaires in case of illiteracy. However, the main reason for the substantial increase in zero trip rates in Denmark can only be related to interviewer performance: an increasing number of interviews were conducted by a small number of interviewers who recorded much higher zero trip rates than the rest; this was also observed in the second stage of the Santiago Mobility Survey and led to a complete reshape of the interviewing force.

In most cases, the response rate has been observed to be declining for continuous crosssectional surveys, as well as for panel surveys. This is a potential cause of discrepancy between national accounts or traffic counts and survey results. For instance in The Netherlands, the response rate fell from 51\% in 1985 to 35\% in 1998. A solution is to redesign the survey, but this introduces some heterogeneity in the time-series. The "respondentfriendly design" introduced in 1999 has maintained the response rate around $70 \%$ in The Netherlands, as well as in the German urban areas where the New Kontiv design is also used. It consists of:

- asking respondent as little as possible (e.g. pre-coded items plus an open answer in case of "miscellaneous" or "other");

- letting respondent choose the survey instrument (face-to-face, phone or preferably mail back), and thus obtain a lower non-response rates for households only accessible by mail; 
- proposing optional follow-up surveys to obtain additional data for specific subgroups (e.g. disabled people) or research topics (e.g. public transport, road accidents);

- decentralising the organization: everybody involved in the interview process has to know as much as possible about the survey.

On the other hand, Table 2 shows that response rates increased in Perth as years went by. This was due to some changes implemented there ${ }^{8}$ :

- different roles were split, i.e., the same person was not charged with the tasks of managing the whole project and the fieldwork team; the person who took over managing the fieldwork team had enough time to do it properly and made a real difference in terms of attitudes, i.e. got the deliverers to care about whether people responded or not;

- a reduction in sample size allowed them to concentrate on keeping a relatively small, but good, team; prior to that, they were always struggling to have enough people and so could not afford to drop any staff who were not "pulling their weight”.

Finally, since the past decade, various monitoring technologies to collect travel behaviour have been set up to help collect data substantially reducing respondent burden. Indeed, increasing the survey period allows researchers to work with smaller samples and collect richer, more in-depth data. GPS surveys have been identified as a potentially ideal solution, as they remove some of the respondents' self-reporting burdens without losing - and in fact, sometimes gaining - detailed data. A paper by Stopher et al. (2008b) related to using GPSbased travel-distance data collected in Adelaide, South Australia, demonstrates the benefits of GPS travel surveys in terms of sample size, accuracy of results and survey costs.

Thus, despite a generally decreasing response rate even for cross-sectional surveys, there are examples where it is stable (New Kontiv) or even increasing (in Perth). This mainly relies on a decentralized organisation and is easier to obtain for a small sample size. New technologies may also help us to gather better multi-day data.

\section{Conclusions}

We have made a thorough worldwide survey of continuous cross-sectional and panel surveys both at the national, regional and urban levels. The experience shows, sadly, that in the large majority of countries these data collection approaches - which constitute and are recognised

\footnotetext{
${ }^{8}$ Tony Richardson (2006) Private Communication.
} 
as the state of practice - have not been attempted, even as research or academic exercises. However, some countries in Europe and Australasia have established these procedures as their main approach for obtaining travel mobility data and others (even in Latin America) have experienced it, with demonstrable success when good practice standards are followed. Also, although not exactly the same, the idea was labelled a landmark by the U.S. Census Bureau.

Of the national and urban continuous mobility surveys considered in this paper, those that have been interrupted have argued the following reasons:

- loss of continuity and motivation of the client's management staff;

- government failure to understand that rigorous (and hence more expensive) procedures are essential to guarantee good quality data;

- poor control on the field work and non-rigorous allocation of surveyed days, leading to low response rates and non-credible proportions of immobile household members;

- in the case of panels, more than a minimum number of waves are difficult to achieve due to attrition.

On the other hand, of those continuous surveys that have been maintained it is possible to gauge that careful attention to staffing problems, and a chronologically and geographically balanced sample scheme, are essential to success. Some other lessons are:

- in the case of panels, it is preferable (although more complex and charged with high respondent burden) that the survey period each year is long enough (seven days is better than two days);

- data quality should not be traded for a high response rate, especially in the case of panels where data quality is crucial for the measurement of changes;

- the drawbacks from selection bias and attrition can be managed with a rotating panel (e.g. each household withdrawn after three years).

- in the case of on-going cross-sectional surveys, possibly the most important issue is keeping interviewers motivated and adhering strictly to the survey good practice standards;

- it has also been found that assigning a pre-allocated day for the travel diaries is far superior to asking questions about the previous day to the interview.

What can be drawn from the examples analyzed in this paper in order to propose a more continuous assessment of mobility trends?

Aiming for a more accurate estimation of trends, we can choose either a household rotating panel survey (e.g. the on-going German Mobility Panel or that conducted previously in The 
Netherlands) or an additional questionnaire to a large sub-sample of a rolling census. In the latter case, the census provides an ideal basis for optimizing the sample as well as for weighting and correcting it (the selection bias of panel surveys are difficult to control).

To get a comprehensive record of mobility (e.g. including holiday periods), a continuous survey should be conducted all over the year. It appears that a sample scheme chronologically and geographically balanced (even if not a panel) can improve the accuracy of time-series data. Finally, it is important to choose a survey design giving a high and non-decreasing response rate (e.g. the New Kontiv); for this, permanent and motivated staffs are essential.

New technologies (e.g. follow-up by GPS or GALILEO in the future) could help surveying during longer periods, providing more accurate data on the spatial and temporal framework of mobility. Recent developments in both data collection and processing using portable, location-aware electronic devices offer the prospect of "extended monitoring panels", in which respondents could participate with comparatively modest response burden for weeks or months. Monitoring technologies are obviously an area of potentially major significance for continuous surveys.

\section{Acknowledgements}

We are grateful to all our colleagues (presenters, chairman, participants, organizing staff) involved in the COST355 meeting on May 20th 2005 in Arcueil, which was the starting point for this research. We also wish to acknowledge the help of Linnea Abramowski, Daniel Bergeron, Ilona Bouhuijs, Neil Kilgren, Martin Lee-Gosselin, Elaine Murakami, Kuniaki Sasaki, Jin-Ru Yen, Johanna Zmud and that of SIKA (Asa Vagland), Socialdata (Stephan Bobinger, Erhardt Erl and Werner Brög) and TUTI (Tony Richardson), who provided us with very useful additional information. Thanks are also due to Ariane Dupont-Kieffer and to four anonymous referees for some very interesting comments, and to Mai Descamps for editing our English on a preliminary version. We finally wish to thank the help of the Research Department (DRI) of the French Ministry for Sustainable Development, which has funded this research and organised an international meeting on this topic (La Défense, 8 October 2007), and that of the Chilean National Fund for Scientific and Technological Research (FONDECYT), through project 1050627, and the Millennium Institute in Complex Engineering Systems (P-05-004-F, CONICYT: FBO16). 


\section{References}

Ampt, E.S. and J. de D. Ortúzar (2004) On best practice in continuous large-scale mobility surveys. Transport Reviews 24, 337-363.

Ampt, E.S., J. de D. Ortúzar and A.J. Richardson (2009) On large-scale ongoing mobility surveys: the state of practice. In P. Bonnel, M.E.H. Lee-Gosselin, J. Zmud and J.-L. Madre (eds.), Transport Survey Methods: Keeping Up With a Changing World. Emerald, Bingley.

Anderson, T., V. Abeywardana, K. Pickering and S. Tipping (2008) National Travel Survey 2007. Technical Report for the UK Department of Transport, National Centre for Social Research, London.

Armoogum, J. and J.L. Madre (1998) Weighting or imputations? The example of non-responses for daily trips in the French NPTS. Journal of Transport Statistics 1, 53-63.

Axhausen, K.W., M. Löchl, R. Schlich, T. Buhl and P. Widmer (2007) Fatigue in long-duration travel diaries. Transportation 34, 143-160.

Axhausen, K.W., A. Zimmermann, S. Schönfelder, G. Rindsfüser and T. Haupt (2002) Observing the rhythms of daily life: a six-week travel diary. Transportation 29, 95-124.

Banders, B. and K. Slootman (1982) A panel for longitudinal research into travel behavior. In S. Carpenter and P.M Jones (eds.), Recent Advances in Travel Demand Analysis. Gower, Aldershot.

Battellino, H. and J. Peachman (2003) The joys and tribulations of a continuous survey. In P.R. Stopher and P.M. Jones (eds.), Transport Survey Quality and Innovation. Pergamon, Amsterdam.

BGC (1991) Het Longitudinaal Verplaatsingsonderzoek - Kenmerken en Gebruik. Bureau Goudappel Coffeng, Projektbureau IVVS. Deventer (in Dutch).

Bradley, M. and J. Zmud (2005) Validating willingness to pay estimates for toll facilities through panel survey methods. $11^{\text {th }}$ International Conference on Travel Behaviour Research. Kyoto, Japan.

Cherchi, E., C. Cirillo and J. de D. Ortúzar (2009) A mixed logit choice model for panel data: accounting for different correlation over time periods. International Choice Modelling Conference, Harrogate, England.

Christensen, L. (2006) Possible explanations for an increasing share of no-trip respondents in the continuous Danish travel survey. In P.R. Stopher and C. Stecher (eds.), Travel Survey Methods: Quality and Future Directions. Elsevier, Oxford.

Cochran, W.G. (1977) Sampling Techniques. Third Edition, John Wiley and Sons, New York.

De Leeuw, E. and W. de Heer (2002) Trends in household survey nonresponse: a longitudinal and international comparison. In M. Groves, D.A. Dillman, J.L. Eltinge and R.J.A. Little (eds.), Survey Nonresponse. John Wiley and Sons, New York.

Golob, T.F., R. Kitamura and L. Long (eds.) (1997) Panels for Transportation Planning - Methods and 
Applications. Academic Press, New York.

Goulias, K.G., N. Kilgren and T. Kim (2003) A decade of longitudinal travel behaviour observation in the Puget Sound region: sample composition, summary statistics and a selection of first order findings. 10th International Conference on Travel Behaviour Research, Lucerne, Switzerland.

Hill, D., A. Munday and J. Henstridge (2004) PARTS. Giving the whole transport picture. Australian Market and Social Research Society Seminar, Sydney, Australia.

Hubert J.-P. (2009) Dans les grandes agglomérations, la mobilité quotidienne des habitants diminue, et elle augmente ailleurs. INSEE Première 1252, National Institute of Statistics, Paris (in French).

Kilgren, N. (1998) Overview of the Puget Sound transportation panel survey (1989-1997). Transportation Panel Survey (Wave7) (www .naw1/its.com/psrc/index.htm).

Kitamura, R. (1990) Panel analysis in transportation planning: an overview. Transportation Research 24A, 401-415.

Kroes, E.P., A.J. Daly, H.F. Gunn and A.I.J.M. van der Hoorn (1996) The opening of the Amsterdam ring road: a case study on short-term effects of removing a bottleneck. Transportation 23, 71-82.

Lee-Gosselin, M.E.H. (2005) A data collection strategy for perceived and observed flexibility in the spatio-temporal organisation of household activities and associated travel. In H.J.P. Timmermans (ed.), Progress in Activity- Based Analysis. Elsevier, Amsterdam.

Lee-Gosselin, M.E.H. and L. Miranda-Moreno (2009) What is different about urban activities of those with access to ICTs? Some early evidence from Québec, Canada. Journal of Transport Geography 17, 104-114.

Madre, J.-L. (2005) Continuous surveys. Minutes of COST355 Seminar, Arcueil, France.

Madre, J.-L. and J. Armoogum (1997) Interview et présence au domicile. XIV Symposium Annuel International sur les Questions de Méthodologie, Statistique Canada, Otawa (in French, with an extended abstract in English).

Madre, J-L, K.W. Axhausen and W. Brög (2010) Immobility in travel diary surveys. Transportation 34, 107-128.

Miranda-Moreno, L. and M.E.H. Lee-Gosselin (2008) A week in the life of baby boomers: how do they see the spatial-temporal organization of their activities and travel? Transportation 35, 629653.

Muñoz, J.C., J. de D. Ortúzar and A. Gschwender (2009) Transantiago: the fall and rise of a radical public transport intervention. In W. Saleh and G. Sammer (eds.), Travel Demand Management and Road User Pricing: Success, Failure and Feasibility. Ashgate, Farnham.

Murakami, E. and C. Ulberg (1997) The Puget Sound transportation panel. In T. Golob, R. Kitamura and L. Long (eds.), Panel for Transportation Planning, Methods and Applications. Academic 
Press, New York.

Murakami, E. and W.T. Watterson (1990) Developing a household travel panel survey for the Puget Sound region. Transportation Research Record 1285, 40-46.

Richardson A.J. and E.S. Ampt (1993) The Victoria integrated travel, activities and land-use toolkit. Vital Working Paper VWP93/1, Transport Research Centre, Melbourne.

Richardson A.J., E.S. Ampt and A.H. Meyburg (1995) Survey Methods for Transport Planning. Eucalyptus Press, Melbourne.

Ruiz, T. (2004) Panel survey approach to measuring season ticket use. Journal of Public Transportation 7, 85-100.

Ruiz, T., H. Timmermans and J.W. Polak (2008) Analysis of attrition and reported immobility in the Madrid-Barcelona Corridor panel survey. 8th International Conference on Survey Methods in Transport, Annecy, France.

Stopher, P.R. (2009) Collecting and processing data from mobile technologies. In P. Bonnel, M. LeeGosselin, J. Zmud and J.-L. Madre (eds.), Travel Survey Methods: Keeping Up With a Changing World. Emerald, Bingley.

Stopher. P.R., E. Clifford and B. Halling (2008a) Evaluating a voluntary travel behaviour change by means of a 3-year GPS panel. Travel Demand Management 2008 Conference, Vienna, Austria.

Stopher, P.R., E. Clifford, N. Swann and Y Zhang (2009) Evaluating travel behaviour changes suggested guidelines and case studies. Transport Policy 16, 315-324.

Stopher, P.R., K. Kockelman, S.P. Greaves, and E. Clifford (2008b) Reducing burden and sample sizes in multiday household travel surveys. Transportation Research Record 2064, 12-18.

Stopher, P.R. and S. Greaves (2006) Guidelines for samplers: measuring a change in behaviour from before and after surveys. Transportation 34, 1-16.

Stopher , P.R. and N. Swann (2008) Six-wave odometer panel for evaluation of voluntary travel behaviour change programs. Transportation Research Record 2049, 119-127.

Stopher, P.R., C.G. Wilmot, C. Stecher and R. Alsnih (2006) Household travel surveys: proposed standard and guidelines. In P.R. Stopher and C. Stecher (eds.), Travel Survey Methods: Quality and Future Directions. Elsevier, Oxford.

Stopher, P.R., Y. Zhang, J. Zhang, and B. Halling (2009). Results of an evaluation of TravelSmart in South Australia. 32nd Australasian Transport Research Forum, Auckland, New Zealand.

Tourangeau, R., M. Zimowski and R. Ghadialy (1997) An Introduction to Panel Surveys in Transportation Studies. NORC, Chicago.

U.S. Census Bureau (2009) Design and Methodology. American Community Survey. U.S. Government Printing Office, Washington, D.C. 
Van Heukelingen, C. (2005) Setting-up a new travel survey concept without causing a trend break. ECTRI Young Researchers' Seminar, The Hague, Holland.

Yañez, M.F., E. Cherchi and J. de D. Ortúzar (2009) Inertia and shock effects on mode choice panel data: implications of the Transantiago implementation. 12th International Conference on Travel Behaviour Research, Jaipur, India.

Yáñez, M.F., E. Cherchi, B.G. Heydecker and J. de D. Ortúzar (2010a) On the treatment of repeated observations in panel data: efficiency of mixed logit parameter estimates. Network and Spatial Economics 10 (in press).

Yañez, M.F., P. Mansilla and J. de D. Ortúzar (2010b) The Santiago panel: measuring the effects of implementing Transantiago. Transportation 37, 125-149.

Zumkeller, D. (2009) The dynamics of change: latest results from the German mobility panel. $12^{\text {th }}$ International Conference on Travel Behaviour Research, Jaipur, India.

Zumkeller, D., B. Chlond and W. Manz (2004) Infrastructure development in Germany under stagnating demand conditions: a new paradigm? Transportation Research Record 1984, 121-128.

Zumkeller D., J.-L. Madre, B. Chlond and J. Armoogum (2006) Panel surveys. In P.R. Stopher and C. Stecher (eds.), Travel Survey Methods: Quality and Future Directions. Elsevier, Oxford.

Zumkeller, D. and P. Ottmann (2009) Moving from cross-sectional to continuous surveying: synthesis of a workshop. In P. Bonnel, M.E.H. Lee-Gosselin, J. Zmud and J.-L. Madre (eds.), Transport Survey Methods: Keeping Up With a Changing World. Emerald, Bingley. 
Table 1 Overview of Continuous Surveys

\begin{tabular}{|c|c|c|c|c|c|c|c|}
\hline Country/Town & Period & Season & Panel & 1 day & 2 or 3 days & 7 days & Long distance \\
\hline \multicolumn{8}{|l|}{ NATIONWIDE SURVEYS } \\
\hline The Netherlands & 1978-onwards & all year & No & $\mathrm{X}$ & before 1985 & & No \\
\hline The Netherlands (LVO) & 1984-1989 & March-Autumn & Yes & & & $\mathrm{X}$ & Yes \\
\hline Great Britain (NTS) & 1988-onwards & all year & No & & & $\mathrm{X}$ & Yes \\
\hline Denmark & $\begin{array}{l}1992-2003 \\
\text { 2006-onwards } \\
\end{array}$ & all year & No & $\mathrm{X}$ & & & $\begin{array}{c}\text { in 1992-2000, } \\
2010 \\
\end{array}$ \\
\hline Sweden & $\begin{array}{l}1994-2001 \\
2010-2011 \\
\end{array}$ & all year & No & $\mathrm{X}$ & & & Yes \\
\hline $\begin{array}{l}\text { German Mobility Panel } \\
\text { (MOP) }\end{array}$ & 1994-onwards & Autumn & Yes & & & $\mathrm{X}$ & in $2000-03$ \\
\hline Italy & 2000-onwards & All year & No & & $\mathrm{X}$ & & No \\
\hline New Zealand & 2002-onwards & all year & No & & $\mathrm{X}$ & & No \\
\hline \multicolumn{8}{|c|}{ SURVEYS IN METROPOLITAN AREAS } \\
\hline $\begin{array}{l}\text { Seattle: Puget Sound } \\
\text { Transportation Panel } \\
\text { (PSTP) }\end{array}$ & 1989-2002 & various & Yes & & $\mathrm{X}$ & & No \\
\hline Montreal & 2009-2011 & all year & no & $\mathrm{X}$ & & & no \\
\hline $\begin{array}{l}\text { Santiago de Chile } \\
\text { Mobility Survey }\end{array}$ & \begin{tabular}{|l|}
$2001-2002$ \\
$2004-2007$ \\
\end{tabular} & all year & No & $\mathrm{X}$ & & & No \\
\hline $\begin{array}{l}\text { Melbourne/Victoria } \\
\text { (VATS and VISTA) }\end{array}$ & \begin{tabular}{|l|}
$1994-2002$, \\
2007,2009 \\
\end{tabular} & all year & No & $\mathrm{X}$ & & & No \\
\hline Sydney (HTS) & 1997-onwards & all year & No & $\mathrm{X}$ & & & No \\
\hline $\begin{array}{l}\text { Perth and Regions Travel } \\
\text { Survey (PARTS) }\end{array}$ & $2002-2006$ & all year & No & $\mathrm{X}$ & & & No \\
\hline $\begin{array}{l}\text { South-East Queensland } \\
\text { Travel Surveys }\end{array}$ & \begin{tabular}{|l} 
2003-2004, \\
2007-onwards \\
\end{tabular} & all year & No & $\mathrm{X}$ & & & No \\
\hline Nuremberg & 1995-onwards & all year & No & $\mathrm{X}$ & & & No \\
\hline $\begin{array}{l}\text { Burgenland and Lower } \\
\text { Austria }\end{array}$ & 1998-onwards & all year & No & $\mathrm{X}$ & & & No \\
\hline Vienna & 1998-onwards & all year & No & $\mathrm{X}$ & & & No \\
\hline
\end{tabular}


Leipzig

Wiesbaden

1999-2001

2000-2003

2000-onwards

all year

all year

all year

No

X

Halle

No

$\mathrm{X}$
$\mathrm{X}$
$\mathrm{X}$ 
Table 2 Sample Size and Response Rates over Time

\begin{tabular}{|c|c|c|c|}
\hline Country/Town & Panel & Sample Size (inds./year) & Response Rate \\
\hline \multicolumn{4}{|l|}{ NATIONWIDE SURVEYS } \\
\hline German Mobility Panel (MOP) & Yes & 1,600 to 2,000 & 5 to $10 \%$ \\
\hline The Netherlands (LVO) & Yes & 3,500 to 4,000 & Low \\
\hline The Netherlands & No & $\begin{array}{l}46,000(1985-93) \\
333,000(1995-98) \\
42,000(2010)\end{array}$ & $\begin{array}{l}\text { 51\% (1985) to 35\%(1998) } \\
\text { 70\% (1999-2009) }\end{array}$ \\
\hline Italy & No & 15,000 & \\
\hline Great Britain (NTS) & No & $\begin{array}{l}10,000(1989-2001) \\
30,000(2002-2008)\end{array}$ & $\begin{array}{l}\text { 80\%(1989-91) } \\
59 \%(2008)\end{array}$ \\
\hline New Zealand & No & $\begin{array}{l}4,400(2002-07) \\
9,200 \text { (2008-onwards) }\end{array}$ & $70 \%$ \\
\hline Denmark & No & $\begin{array}{l}25,000 \text { before } 2002 \\
20,000 \text { in } 2002-03 \text { and 2006- } \\
2009 \\
40,000 \text { since June } 2009\end{array}$ & $\begin{array}{l}83 \%(1998) ; \\
75 \%(2001) \\
70 \% \text { after } 2006\end{array}$ \\
\hline Sweden & No & $\begin{array}{l}11,000(1995-98) \\
8,000(1999-2001)\end{array}$ & $70 \%(1999-2001)$ \\
\hline \multicolumn{4}{|l|}{ SURVEYS IN METROPOLITAN AREAS } \\
\hline $\begin{array}{l}\text { Seattle: Puget Sound Transportation Panel } \\
\text { (PSTP) }\end{array}$ & Yes & 3,000 to 4,000 & \\
\hline Montreal & No & 30,000 & \\
\hline Santiago de Chile Mobility Survey & No & 30,000(2002), 10,000 onwards & $70 \%$ (2002), 45\% (2007) in 2002 \\
\hline $\begin{array}{l}\text { Melbourne: Victorian Activity and Travel } \\
\text { Survey (VATS) }\end{array}$ & No & 10,000 to 12,000 & 60\% (1994) 45\% (1999) 25\% (2002) \\
\hline Sydney (HTS) & No & 10,000 & 75\%(1997); 68\%(1999); 63\%(2004) \\
\hline Perth and Regions Travel Survey (PARTS) & No & 5,000 & 48\%(2003); 49\%(2004); 57\%(2005) \\
\hline
\end{tabular}




\begin{tabular}{|l|l|l|l|}
\hline & & & $60 \%$ (2006) \\
\hline Halle & No & 10,500 to 15,000 & $82 \%$ (average) \\
\hline Nuremberg & No & 14,500 to 19,000 & $87 \%$ (average) \\
\hline Burgenland and Lower Austria & No & 39,000 & \\
\hline Vienna & No & 19,000 & \\
\hline Wiesbaden & No & 5,000 & \\
\hline Leipzig & No & 5,300 & $80 \%$ (average) \\
\hline
\end{tabular}


